\title{
Toplum Çevirmenliğinde Fikir Madenciliği ve Duygu Analizi
}

\author{
Olcay Şener Erkırtaya, b, Ceyda Ünalc
}

\section{Özet}

Teknolojinin hayatımıza büyük bir katkı sağladığı ve toplum üzerinde önemli bir etkiye sahip olduğu bir gerçektir. Teknolojinin gelişmesiyle birlikte internette üretilen veri miktarı da artmıştır. Özellikle sosyal medya, kullanıcıların görüş ve duygularını rahatlıkla ifade edebildiği önemli bir mecraya dönüşmüştür. Bu noktada, birçok alanda kullanıcıların internette paylaştıkları duygu ve düşünceleri Doğal Dil İşleme (DDİ)'nin alanlarından biri olan "fikir madenciliği" yöntemiyle incelenmekte ve kullanıcıların duygu analizi yapılmaktadır. Bu çalışmanın amacı da toplum çevirmenlerinin duygu ve düşüncelerinin fikir madenciliği yöntemiyle incelenebileceğine dair bir yaklaşım sunmaktır. Bir diğer deyişle, daha çok bilgisayar bilimleri ve yönetim bilişim sistemleri disiplinlerinde kullanılan fikir madenciliği ve duygu analizi yöntemlerini tanıtarak, toplum çevirmenliği araştırmalarına yeni bir bakış açısı sunmak hedeflenmiştir. Bu amaçla, fikir madenciliği ile duygu analizi yönteminin toplum çevirmenliği araştırmalarına katkıları betimleyici bir yaklaşımla tartışılmaktadır.
Anahtar Kelimeler

Toplum Çevirmenliği

Makine Öğrenmesi

Fikir Madenciliği

Duygu Analizi

Makale Hakkında

Geliş Tarihi: 03.03.2021

Kabul Tarihi: 24.09.2021

Doi: 10.18026/cbayarsos.890384

\section{Opinion Mining and Sentiment Analysis in Community Interpreting}

\begin{abstract}
It is a fact that technology has made a great contribution to our lives and has a great impact on society. With the development of technology, the amount of data created on the internet has also increased. In particular, social media has turned into an important medium where users can share their beliefs and opinions freely. In this regard, many different sectors have started scrutinizing users' opinions and emotions with the "opinion mining" method which is one of the fields of Natural Language Processing (NLP). The objective of this paper is to present an approach towards analyzing the community interpreters' emotions and opinions using "opinion mining" method. In other words, this paper aims at providing a new insight into community interpreting research by introducing opinion mining and sentiment analysis methods, which are mainly used in Computer Science and Management Information Systems. With this aim in mind, the contributions of the opinion mining method to community interpreting research have been discussed with a descriptive approach.
\end{abstract}

Keywords

Community Interpreting

Machine Learning

Opinion Mining

Sentiment Analysis

About Article

Received: 03.03.2021

Accepted: 24.09 .2021

Doi: 10.18026/cbayarsos. 890384

\footnotetext{
a senerr.olcay@gmail.com

b Araştırma Görevlisi, Dokuz Eylül Üniversitesi, Edebiyat Fakültesi, İngilizce Mütercim ve Tercümanlık Bölümü, orcid.org/0000-0002-5971-2585

c Araştırma Görevlisi, Dokuz Eylül Üniversitesi, İktisadi ve İdari Bilimler Fakültesi, Yönetim Bilişim Sistemleri Bölümü, orcid.org/0000-0002-5503- 


\section{Giriş}

Teknoloji hayatımızın ayrılmaz bir parçasıdır. Teknolojinin icadı yalnızca yaşam koşullarımızı değiştirmekle kalmamış; bilginin yayılma ve ulaşılma biçimini de değiştirmiştir. Teknoloji aynı zamanda, haberleşme başta olmak üzere alışveriş, bilgi edinme, eğitim, sağlık, vb. gibi birçok alanda kolaylık sağlamaktadır. Teknolojinin hızla gelişmesi, üretilen veri miktarının da artmasına sebep olmuştur. We are Social ve Hootsuite tarafından ortaya konulan “Dijital 2021 Türkiye" raporunda, Türkiye'deki internet kullanıcılarının sayısının 67 milyon olduğu, bunun da tüm nüfusa oranının \%77 olduğu vurgulanmaktadır. Bunun yanında, bir Türk internet kullanıcısının günde ortalama sekiz saat internet kullandığı ve bunun da üç saatini sosyal medyada geçirdiği belirlenmiştir. Global ölçekte ise, Ocak 2020 ve Ocak 2021 tarihleri arasında aktif sosyal medya kullanıcılarının sayısının \%13,2 oranında arttığ1 vurgulanmıştır (We are Social, 2021). İstatistiklerden de anlaşılabileceği üzere, sosyal medya, kullanıcılar için dijital dünyayla buluşma bağlamında bir kilometre taşı olarak düşünülebilir. Bu kadar kullanıcının aktif olarak bulunduğu mecrada, kişiler istedikleri yer ve zamanda farklı içerikler üretip, belli konular hakkında duygu, düşünce ve görüşlerini rahatlıkla belirtebilmektedir. Bu anlamda sosyal medya, kişilerin bakış açılarını ifade ettikleri vazgeçilmez bir veri kaynağı olarak düşünülebilir. Gelişen teknolojiyle birlikte, bu verilerden yola çıarak kişilerin duygu, düşünce ve görüşlerini analiz etmek ve bunları stratejik hedefler doğrultusunda kullanmak mümkün hale gelmiştir. Doğal Dil İşleme ve metin madenciliğinin önemli kullanım alanlarından biri olan fikir madenciliği ve duygu analizi de tam da bu noktada gerek sektör temsilcilerinin gerekse araştırmacıların ilgisini çekmeye başlamıştır. Aynı şekilde duygusallığın baskın olduğu toplum çevirmenliğinde de çevirmenlerin duygudurumu, çeviri performanslarını ve çeviri kalitelerini etkileyebilmektedir. Bu noktada da çevirmenlerin çalıştıkları ortamla ilgili duygu ve düşüncelerini net bir şekilde ortaya koymak çeviri kalitesinin artmasına da katkı sağlayacaktır. Bu sebeple bu makalenin amacı sağlık, turizm, finans, pazarlama, politika vb. gibi başka alanlarda kullanılan bu yöntemi sözlü çeviri çalışmalarına da entegre etmektir. Böylece, çevirmenlerin anket ve mülakat ile elde edilen görüşlerinden çok daha derinlemesine bir analiz elde etmek mümkün olabilecektir. Bu bağlamda veri bilimi ve çeviribilim alanlarının birbirlerini besleyen taraflarından yararlanılıp, her iki alanın kesişiminde, betimleyici bir yaklaşım ortaya koymak hedeflenmektedir. Böylelikle disiplinler arası bir araştırma çerçevesi oluşturulabilecektir. Bir diğer ifadeyle, hâlihazırda bilgisayar bilimleri veya yönetim bilişim sistemleri gibi alanlarda sıklıkla kullanılan fikir madenciliği ve duygu analizi yöntemlerini, çeviribilim alanına katkıları açısından incelemek hedeflenmektedir.

$\mathrm{Bu}$ çalışmada ilk olarak, sözlü çeviri çalışmalarında teknolojinin öneminden bahsedilerek Türkiye'de sözlü çeviri teknolojileri üzerine yapılan çalışmalar incelenmiştir. Bunun yanında toplum çevirmenliği ve çeviride duygu faktörü örneklerle ele alınmıştır. Bir diğer bölümde doğal dil işleme yöntemi, gelişim evreleri de dikkate alınarak tanıtılmıştır. Sonraki bölümlerde çalışma; fikir madenciliği ve duygu analizi kavramları, duygu analizi düzeyleri, duygu analizinde kullanılan yöntemler ve toplum çevirmenliği araştırmalarında fikir madenciliği çerçevesinde organize edilmiştir. Şekil 1'de makalenin yapısı ve organizasyonu görülmektedir. Son olarak sonuç bölümünde ise, çalışma genel yapısıyla ele alınmış ve gelecek çalışmalar için de öneriler sunulmuştur. 


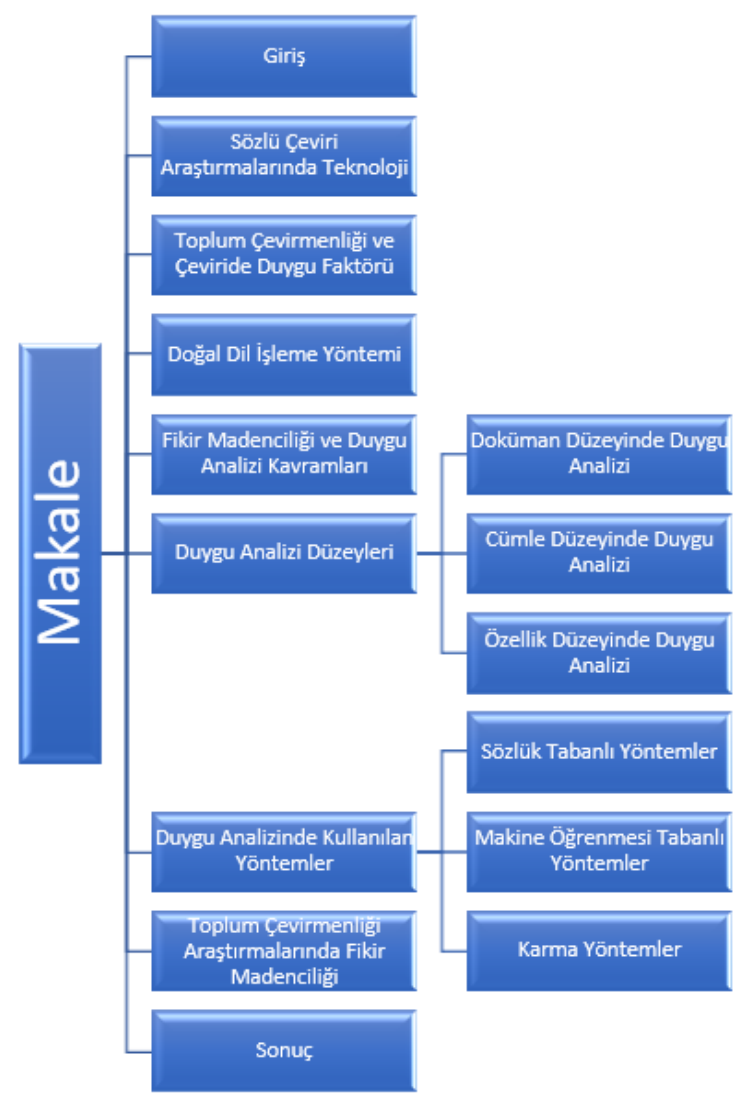

Şekil 1. Makale Yapısı ve Organizasyonu

Kaynak: Yazarlar

\section{Sözlü Çeviri Araştırmalarında Teknoloji}

Teknolojinin sözlü çeviri çalışmalarında yeni bir araştırma alanı olmadığı şüphesizdir. Simultane çevirinin doğuşu ve gelişiminin teknolojiyle doğrudan bağlantılı olması ise bu durumun en büyük kanıtı olarak gösterilebilir (Liu, 2018, p.20). Mikrofon kullanımı ile kayıt cihazının icadı çevirmenin sesinin daha geniş kitlelere yayılmasını ve dolayısıyla çevrilen konuşmaların daha geniş kesim tarafından duyulmasına olanak sağlamıştır (a.g.e). Teknolojik gelişmelerle birlikte sözlü çevirinin uygulama şeklinde de önemli gelişmeler yaşanmıştır (Pöchhacker, 2004, p. 201). Fantinuoli (2018, p.2) sözlü çeviride özellikle iki önemli teknolojik dönüm noktası olduğunu belirtmektedir. Bunların ilki IBM (Uluslararası İş Makineleri) adı verilen bilişim teknolojisi şirketi tarafından tasarlanan ve ilk defa Sovyet Sosyalist Cumhuriyetler Birliği'nde gerçekleştirilen Altıncı Komintern Kongresi'nde (1928) ve Uluslararası Emek Konferansı'nda uygulanan simultane tercüme ekipmanı olmuştur. İkinci dönüm noktası ise kısaca WWW olarak bilinen World Wide Web (Dünya Çapında Ağ)'in geliştirilmesidir (a.g.e). Bu gelişme, çevirmenler için de bilgiye daha kolay erişebilme açısından büyük bir kolaylık sağlamıştır. Tabletler ve diz üstü bilgisayarlar gibi birçok araç çevirmenler tarafından konferansa hazırlık aşamasında yaygın olarak kullanılmaktadır. Yine bu araçların haricinde çevrimiçi sözlükler ve çeşitli web siteleri de çevirmenlerin bilgiye ulaşmasını hızlandırmaktadır. Mouzourakis (2000, p.4) de konferans çevirmenlerinin görevlerinin sadece diller arası çeviri yapmak olmadığını, çeviri öncesinde de gerekli bilgiye ulaşma anlamında hazırlık yapmak zorunda olduğunu belirtmiştir. Dolayısıyla internetin 
yaygınlaşmasıyla birlikte bilgiye erişim çevirmenler için daha kolay hale gelmiştir. Bu konuda Donovan (2006) da benzer bir yaklaşım sergilemiştir:

[...] İnternet hazır erişim konferans hazırlı̆̆ını ve konferansla ilgili arka plan bilgisi edinme şeklini tamamen değiştirmiştir. Eskiden çevirmenler bilginin izini sürmek için saatler harcayıp güncel bilgilere erişmekte zorluk yaşarken, şu an çok fazla bilgiyle karşı karşıyadırlar. Zorluk, bilgiye erişmekte değil; salt bilgiyi ortaya çıkarmakta yatmaktadır. (Donovan, 2006, p.4-5)

Diğer yandan, Sabine Braun (2019, p.16) sözlü çeviri teknolojilerini üç farklı kategori altında incelemektedir. Bunlardan ilki sözlü çeviri hizmetlerine erişim imkânı sağlayan teknolojiyi betimleyen "uzaktan çeviri" ("distance" veya "remote interpreting"), diğer kategori çevirmenlerin çeviriye hazırlanmalarına katkı sağlayan yukarıdaki örneklerde de belirtilen "teknoloji destekli çeviri" (technology-supported interpreting) ve üçüncü kategori ise insan çevirisi yerine kullanılan teknolojileri içeren "makine çevirisi" (machine interpreting)'dir. Benzer şekilde Fantinuoli (2018, p.4) "bilgisayar destekli çeviri" (computer-aided interpreting (CAI)", "uzaktan çeviri" (remote interpreting) ve "makine (sözlü) çevirisi" (machine interpreting) olmak üzere üç sinıflandırmadan bahsetmektedir.

Bu üç kategori haricinde Fantinuoli (2018, p.6) yeni bir teknolojik dönüşümü vurgulamaktadır. Özellikle doğal dil işleme ile bilgi ve iletişim teknolojilerinin sunduğu yeni teknolojilerle şirketlerin kullanıcı talep ve tepkilerine yanıt verebildiklerinden bahsetmektedir (a.g.e). Başta turizm ve sağlık olmak üzere birçok alanda özellikle kullanıcıların duygularını, taleplerini ölçen yazılımlar kullanılmaktadır. Fantinuoli (2018, p.4) bilgisayar destekli çeviri araçlarının terminoloji, sözlükçe oluşturma gibi vakit alacak görevler konusunda çevirmenlere vakit kazandırarak çevirmenlerin çalışma koşullarını iyileştirme amacıyla ortaya konulduğunu ileri sürmektedir. Bu araçlar sayesinde çevirmenlerin çalışma koşullarının iyileşmesi de hem çeviri öncesinde hem çeviri sırasındaki performanslarını olumlu yönde etkileyerek çeviri kalitesinin artmasına yardımcı olacağını belirtmektedir (a.ge.). Çevirmenlerin çalışma durumunun iyileştirilmesi kadar duygudurumunun ve nihayetinde negatif duyguların oluşumuna sebep olan durumların belirlenerek pozitif duygulara döndürmek de çevirmenin performansının ve çeviri kalitesinin artması hususunda son derece önem arz etmektedir. Sanlı (2019, s.19), duygudurumun psikoloji alanında önemli bir yere sahip olduğunu ve psikoloji literatüründe "ruhsal durum" u ifade ettiğini belirtmektedir. Dolayısıyla, bu çalışmanın amacı sözlü çeviri çalışmalarında, özellikle duygudurumun daha yoğun olarak yaşandığ 1 toplum çevirmenliği alanında, çevirmenlerin duygularının daha şeffaf bir şekilde ölçülmesine olanak sağlayabilen bir yöntem önerisinde bulunmaktır. Diğer bir deyişle, sözlü çeviri araştırmalarında nasıl uygulanabileceğine yönelik öneride bulunmaktır.

Alanyazına bakılacak olursa; Türkiye' de yazılı çeviri teknolojileri üzerine yapılan çalışmaların yanı sıra (örneğin, Şahin, 2013, 2015, 2016; Canım-Alkan, 2013, 2017,) sözlü çeviri araştırmalarında da teknolojiyle ilgili çalışmalar mevcuttur. Öncelikle Mehmet Şahin ve Şeyda Eraslan (2017) üç boyutlu sanal ortamlarda sözlü çeviri eğitiminde yeni uygulamalar ortaya koymayı hedefledikleri TÜBİTAK destekli (Proje No: 114K718) "Sanal Dünyalarda Sözlü Çeviri ve Sözlü Çeviri Eğitimi" başlıklı bir proje tanıtmışlardır. Bu proje kapsamında Türkiye'deki sözlü çeviri eğitimi uygulamalarının genel durumları, alandaki eksiklikleri ve beklentileri profesyonel çevirmenlere ve öğrencilere uygulanan anket ve deneylerle ortaya 
koyularak daha güçlü bir bilimsel öğretme ortamının oluşturulması amaçlanmıştır (Şahin \& Eraslan, 2017, s.1).

Esra Öztürk (2017) bu alanda çalışma yapan bir diğer araştırmacıdır ve Öztürk (2017) teknolojinin sözlü çeviri eğitimindeki rolüne odaklanarak, uzaktan çevirinin sözlü çeviri eğitimine etkisi ve kullanımına genel bir bakış sunmaktadır. Uzaktan çeviri konusundan hareketle Öztürk (2017), Türkiye'deki eğitim kurumlarındaki sözlü çeviri eğitim müfredatlarının yeni medya çağına henüz iyi yapılandırılmamış olduğunu öne sürmektedir.

Diğer yandan, İbrahim Balkul ve Şule Akıncı (2019) sözlü çeviri alanında kullanılan teknolojik araçların kullanımını, kullanım amacını ve bu teknolojiden faydalanan kullanıcı kitlesinin profilini inceleyerek sistematik bir siniflandırma ortaya koymayı hedeflemektedir. $\mathrm{Bu}$ bağlamda sözlü çeviride kullanılan teknolojik araçlar, "farklı çeviri türlerinde kullanılan çeviri teknolojileri", "sözlü çeviride otomasyon derecesine göre teknolojik araçlar", "süreç odaklı sözlü çeviri teknolojileri" ve "sözlü çeviri eğitiminde kullanılan teknolojik araçlar" olmak üzere dört ana kategori altında analiz edilmiştir (Balkul \& Akıncı, 2019, ss.395- 403).

Son olarak, Özüm Arzık- Erzurumlu (2020) sözlü çeviri eğitiminde podcast kullanımının katkılarını incelemiştir. Son sınıf öğrencileriyle pilot çalışma olarak yürüttüğü bu çalışmasında Arzık-Erzurumlu (2020), podcast’lerin birçok anlamda öğrencilere katkı sunduğunu ortaya koymuştur. Elde edilen sonuçlara göre öğrencilerin hayat boyu öğrenme yetkinliği ile kültürel yetkinlikler kazandığı ortaya çıkmıştır.

Yukarıda ele alınan çalışmalara bakıldığında, teknolojinin sözlü çeviri çalışmalarında önemli bir yeri olmasına rağmen, alanyazında Türkiye'de özellikle sözlü çeviri alanında teknoloji kullanımıyla ilgili bir boşluk olduğu göze çarpmaktadır. Dolayısıyla bu çalışma, birçok farklı sektör tarafından kullanıcı odaklı hizmet/ürün kalitesini artırmaya yönelik faydalanılan fikir madenciliği ve duygu analizi yöntemini kavramsal olarak açılayarak hem alanyazındaki eksikliği doldurmaya katkı sağlamayı hem de özellikle toplum çevirmenliği araştırmalarında yeni bir uygulama alanı sunmayı hedeflemektedir.

\section{Toplum Çevirmenliği ve Çeviride Duygu Faktörü}

Küreselleşme ve modern ulaşım araçlarının gelişmesiyle birlikte yalnızca eğitim, sağlık, iş vb. gibi sebeplerden dolayı değil; aynı zamanda doğa veya insan kaynaklı afetlerden kaçmak için de ülkeler arası hareketlilik artmıştır (Corsellis, 2008, p.1). Böylelikle, çokdillilik ve çokkültürlülük artmış; sosyal hizmet ortamlarında dilsel ve kültürel bariyeri ortadan kaldıracak toplum çevirmenlerine ihtiyaç duyulmaya başlanmıştır. En yalın haliyle toplum çevirmenliği, kurumlarda aynı dili konuşamayan sosyal hizmet sağlayıcıları ile halk arasında yapılan çeviri türüdür (Pöchhacker, 1999, pp.126- 127). Toplum çevirmenliği hizmeti okul, hastane, polis merkezi veya göçmen büroları gibi toplumsal hizmet sunan birçok kurumda sağlanmaktadır (Pöllabauer, 2002, p.287).

Toplum çevirmenliğini konferans çevirmenliğinden ayıran birçok farklı nokta vardır. Çeviri yönü, çeviri modu ve çevirmen sayısı bu farklılıklardan bazılarını oluşturmaktadır (Hale, 2007, p.32). Ancak bir diğer önemli farklılık, toplum çevirmenliğinde duygu boyutunun diğer sözlü çeviri ortamlarına göre daha yoğun olması ve çevirmenin bu olumsuz koşullar altında yetkinlik göstererek taraflar arasındaki iletişimi sağlaması gerektiğidir (Şan \& Kahraman 
Duru, 2020, s.818). Örneğin, Kahraman (2010) mültecilere verilen çeviri hizmetinde işin duygusallığına vurgu yaparak şunları söylemiştir:

Bir mülteci kampında sığınma başvurusunda bulunanlara, kampın tüm olumsuz koşullarına karşın çeviri yapmak da çevirmeni insani boyutta zorlayabilir. Örneğin, tecavüze uğramış, töre cinayetinden kaçan bir kadının ya da işkence görmüş bir insanın görüşmesi sırasında yapılan çeviriler toplum çevirmenliğinde karşılaşılan vakalardan yalnızca birkaçıdır. Tüm bu çeviri ortamlarında karşılaşılan koşullar çevirmeni ister istemez fiziksel ve psikolojik olarak zorlayacaktır. Bu durum çevirinin niteliğini ve çevirmenin karar alma süreçlerini etkileyebilir (Kahraman, 2010, s.41).

Mülteci çevirmenliğinde olduğu gibi hastane çevirmenliğinde de doktor-hasta görüşmeleri sırasında psikolojik faktörlerin çevirmenlerin çeviri stratejilerine etki ettiği, dolayısıyla, empati göstermeleri gerektiği ortaya konulmuştur (Şener, 2017). Benzer şekilde Valero- Garces (2005) duygusallığın yoğun olduğu bir ortamda çalışmanın sonuçlarını meslekte, işyerinde ve işyeri dışındaki ortamda oluşabilecek problemler açısından üç farklı kategoride ele almaktadır. Duygusal değişiklik, mesleki anlamda travmatik karşı aktarım, anksiyete, stres, yanlış algılama, kalp rahatsızlıkları ve motivasyon eksikliği, fiziksel ve zihinsel yorgunluk, enerji kaybı gibi belirtilerle tükenmişlik sendromunun görülmesine sebep olabilmektedir. İşyerinde ise devamsızlık, pozisyonu/ kurumu terk etme, ikili ilişkilerde çatışma gibi sıkıntılara yol açabilirken, işyeri dişında ise aile ilişkilerinde sıkıntılara ve temsili travmatizasyon gibi problemlere yol açabilmektedir (Valero- Garces, 2005, p.4). Blair ve Ramones (1996) de özellikle istismar ve travma kurbanlarıyla çalışan sağlık çalışanlarında anksiyete, depresyon, yabancılaşma, paranoya gibi ciddi sıkıntılar yaşanabileceğini öne sürmektedir. Tıpkı sağlık çalışanlarında olduğu gibi çevirmenlerde de bu etkileri görebilmek mümkündür. Kendisine psikolojik olarak zarar vermesinin yanı sıra çeviri performansını ve kalitesini de etkileyebilmektedir. Duman (2019, s.181) çevirmenlerin sahip olduğu olumsuz düşüncelerin çevirmenin bilişsel süreçlerine ekstra yük getireceğini öne sürmektedir. Bu sebeple, çevirmenin olumsuz duygularının arka planını ortaya koyarak duygudurumunun düzenlenmesi son derece önemlidir (a.g.e.). Özellikle duygusal faktörlerin yoğun olduğu toplum çevirmenliğinde çevirmenin çalıştığ ortam ve çeviri yaptığ kitle ile ilgili duygudurumunun belirlenmesi, varsa negatif düşüncelerin ortaya çıarılarak bu düşüncelerin olumluya dönmesi yönünde iyileştirme çalışmalarının yapılması gerekmektedir. Böylelikle, çevirmenin üzerindeki duygusal yük azalacak ve çeviri kalitesi olumlu yönde etkilenebilecektir. Bu sebeple, bu çalışmada çevirmenlerin duygu ve düşüncelerinin nitel araştırma yöntemleriyle incelenebileceği gibi, istatistiksel yöntemlerle de incelenebileceği öne sürülmekte ve çoğunlukla yapay öğrenme uygulamalarında kullanılan doğal dil işlemenin alanlarından biri olan fikir madenciliği ve duygu analizi yöntemi sözlü çeviri araştırmalarına entegre edilmektedir. Bu amaçla, bir sonraki bölümde doğal dil işleme ve tarihçesine değinilmektedir.

\section{Doğal Dil İşleme (DDİ) Kavramı}

Doğal Dil İşleme (DDİ), Yapay Zekâ (YZ) kapsamında yer alan bir araştırma alanıdır. DDİ özellikle mühendislik ve dilbilim araştırmalarının ortak noktalarıyla son derece ilgili olan süreçleri uygulamak adına, insan (doğal) dillerini işlemek veya anlamak amaciyla kullanılan otomatize süreçleri incelemektedir. Bir diğer deyişle, DDİ dillerin bilişsel yönünü anlamayı hedeflemektedir. Mühendislik alanı açısından bakıldığında, bilgisayarlar ve insan dillerini 
bağlayan orijinal uygulamaları tasarlayan disiplinler arası bir alan olarak ele alınmaktadır (Deng \& Liu, 2018, p.1).

Goldberg (2017), DDİ'yi yapılandırılmamış bir dil verisi girdisi veya yapılandırılmamış doğal dil verisi çıktısı olarak alan metot ve algoritmaları tasarlayan bir alan olarak tanımlamaktadır. Ayrıca, makinelerin, özellikle de bilgisayarların işleyemediği bu zorlu bilgileri insanların kolaylıkla işleyebildiği vurgulanmaktadır. Bunun sebebi olarak da yazar, bir dili anlamanın, ifade etmenin ve nihayetinde yorumlamanın bilgisayarlar için oldukça karmaşık ve zorlu bir süreç olduğunu ileri sürmektedir. Ayrıca, makineler kuralları anlama ve betimleme konusunda yeterli olmakla birlikte dili anlamlandırma konusunda başarısızdır.

DDİ'nin amacl, doğal dilleri geliştirip anlarken oluşan problemleri otomatik olarak incelemektir. DDİ, insanlar tarafından üretilen sesleri ve metinleri işlerken insan-bilgisayar etkileşimine katkı sağlamaktadır (Young vd., 2018, p.25). Doğal dil işleme araştırmaları iki kategoriye ayrılmaktadır. İlk kategori ses (sinyal) işleme, diğer kategori ise dil işleme olarak adlandırılmaktadır. Ses işleme, dilin fonolojik özelliklerinin ses teknolojileri yardımıyla incelenerek ses ve metin arasında yapılan çeviri olarak tanımlanmaktadır (Kuşçu, 2015, s.50).

DDİ araştırmaları ilk olarak “Bilgisayarlı Dilbilim” alanında yapılmıştır. Bilgisayarlı dilbilim sözlü veya yazılı dili anlamayı, matematiksel olarak ifade etmeyi amaçlayan ve bu amaç doğrultusunda metotlar, modeller ve araçlar öneren disiplinler arası bir bilimdir. 1950'li yıllarda Rusça makalelerin İngilizceye otomatik olarak çevrilmesi ihtiyacıyla Amerika'da başlayan bilgisayarlı dilbilim çalışmaları şu an Türkçe dahil birçok dilde yapılmaktadır (Uçan \& Akçapınar Sezer, 2020, s.194). Makine çevirisi üzerine ilk konferans MIT tarafından 1952 yılında düzenlenmesine ve bu alanda "Mechanical Translation" (Mekanik Çeviri) adlı ilk dergi 1954 yılında yayın hayatına başlamasına rağmen ‘Bilgisayarlı Dilbilim’ terimi ilk olarak 1960’lı yıllarda kullanılmaya başlanmıştır. Bununla bağlantılı olarak 1962 yılında Makine Çevirisi ve Hesaplamalı Dilbilim Derneği (Machine Translation and Computational Linguistics) kurulmuştur. Makine çevirisi tarihinde dönüm noktası olabilecek gelişme, 1966 yılında Amerikan Ulusal Bilimler Akademisi tarafından kurulan ve Türkçesi Otomatik Dil İşleme Danışma Kurulu olan ALPAC (Automatic Language Processing Advisory Committe) raporunun Kasım 1966'da yayınlanmasıdır. ABD'de yaklaşık yirmi yıl boyunca makine çevirisi araştırmalarının önemli ölçüde fonlanmasına son vermek amacıyla ortaya konulan rapor, genel kamuoyuna ve bilim camiasının geri kalanına makine çevirisinin bir hayal olduğunu vurgulamaktaydı. Buna rağmen, ABD'de makine çevirileri araştırmaları 1966'da tamamen ve aniden kesilmemiştir. ALPAC aynı zamanda, insan çeviri sürecini hızlandırmak, çeşitli türden makine destekli çevirilerin hı ve maliyetlerinin değerlendirilmesinin desteklenmesi gerektiğini önermiştir (Poibeau, 2017, p.77).

1980'li yıllardan itibaren makine çevirisi araştırmaları bazı uygulama alanlarında daha da önem kazanmıştır. Sonrasında Machine Translation (Makine Çevirisi) adını alan “Computers and Translation" (Bilgisayarlar ve Çeviri) Dergisi araştırmaçları bu tür çalışmalar yapmaları konusunda teşvik etmişlerdir. Yapay zekâ geliştikçe, bu tür araştırmalar teknolojik uygulamalarla desteklenmiş ve dilbilimciler için "İstatistiksel Doğal Dil İşleme" yöntemleri ortaya konulmuştur (Kay, 2004, p.25).

Bilgi teknolojilerindeki gelişmeler bilgisayarlı dilbilim çalışmalarına hız kazandırmıştır. Doğal Dil İşleme (DDİ) adı verilen bu yeni bilim alanı ilk olarak insan- bilgisayar etkileşiminde doğal dilleri kullanmak üzere başlatılmıştır. İnsan konuşmasını anlayabilmesi ve anlaşılabilir bir 
dilde konuşarak insanlarla etkileşime geçebilmesi için, bilgisayarın bir dilin tüm özelliklerini ve kurallarını iyi bilmesi gerekmektedir. Bir diğer deyişle, dilin tüm özellik ve kurallarının bilgisayarlara tanımlanması gerekmektedir. Dilbilimciler, bir dilin yapısını oluşturan dört ana konuya (fonoloji, morfoloji, sözdizimi ve anlambilim) odaklanarak dilin tüm özelliklerini ve kurallarını ortaya koymaya çalışmaktadır. Bu çalışmalara paralel olarak, bir dilin zaman içerisindeki evrimine de odaklanmaktadırlar. Doğal dil işleme alanında çalışan bilgisayar uzmanları veya veri bilimciler dilbilimcilerin elde ettiği sonuçları kullanarak bilgisayarlar yardımıyla dili işlemeye çalışmaktadırlar.

Son zamanlarda oldukça popüler olan "Metin Madenciliği” de DDİ araştırmaları kapsamında yer almaktadır. Metin madenciliği sayesinde çoğunlukla internet üzerindeki duygu, düşünce ve görüşleri işlemek ve bunlardan anlam çıkarmak mümkün hale gelmektedir. Bu bağlamda metin madenciliği; metinsel dokümanlardaki henüz ortaya çıkarılmamış bilgiyi, bilgisayar sistemleri aracılığıyla çıkarma sürecini veya bilginin keşfini ortaya çıkarmak için kullanılan bir yöntemdir. Doğal dil işleme metotlarıyla (makine öğrenmesi tabanlı yöntemler) metinsel dokümanlardan bilgi çıkarmak için kullanılan bu disiplinin asıl amacı işlenmemiş veriden, yani belirli bir formatla tanımlanamayan, yapılandırılmamış verilerden bir çıkarım yapmaktır (Çalış vd., 2013, s.3). Metin madenciliği metotlarının temelinde matematiksel ve istatistiksel metotlar bulunmaktadir.

Son yıllarda sosyal medya; metin madenciliği çalışmalarında önemli bir veri kaynağı olarak kullanılmaktadır. Sosyal medyada kullanıcılar tarafından üretilen içeriklerin analizi kurumlar için içgörü sunmaktadır. Özellikle duygu analizi yöntemi ile bahsedilen konu hakkında kişilerin olumlu, olumsuz veya nötr görüşlere sahip olup olmadığı başarılı bir şekilde belirlenmektedir. Bu yöntem sadece sosyal medya bağlamında değil, tüm metinsel format veya dokümanlar için uygulanabilmektedir. Bu anlamda Nvivo, MaxQD, Atlas.ti gibi araçlar bağlamsal inceleme ve içerik analizi için sıklıkla kullanılmakla beraber, makine öğrenmesi tabanlı uygulamalarda; metin madenciliği ve duygu analizi noktasında RapidMiner, KNIME ve WEKA gibi araçlar kullanılmaktadır. Duygu analizi konusunda literatürde birçok önemli çalışma mevcuttur.

Pınarbaşı ve Canbolat (2018) mobil uygulamalar hakkındaki görüşleri çıkarmak ve analiz etmek için metin madenciliği yöntemlerini kullanmışlardır. Araştırmada iOS platformu veri kaynağı olarak seçilmiştir. Sonuç olarak, artırılmış gerçeklik, müzik, sağlıklı yaşam, eğlence, fotoğraf-video, medikal, yardımcı uygulamalar (utilities), sosyal ağlar ve navigasyon olmak üzere dokuz uygulama kategorisi incelenmiş ve artırılmış gerçeklik (Augmented Reality) uygulamalarında diğer kategorilere göre duygu anlamında daha belirgin ayrımların olduğu gözlenmiştir. Ayrıca, betimsel istatistik ve korelasyon yöntemleri uygulanmıştır.

Çılgın ve diğerleri (2020), sosyal medya etkileşimi ve Bitcoin fiyatları arasındaki ilişkiyi incelemiştir. Araştırmada, 06.10.2018-19.05.2019 tarihleri arasında Twitter kullanıcıları tarafından paylaşılan toplam 2,819,784 tweet incelenmiştir. Çalışma kapsamında, duygu analizi için metin madenciliği yöntemleri ile metin sınıflandırması için makine öğrenmesi yaklaşımları olmak üzere iki aşamalı bir süreç uygulanmıştır. Bunun sonucunda, metin sınıflandırma; yapay sinir ağları yöntemiyle \%90 doğrulukla gerçekleştirilmiştir. Sosyal medya paylaşımları ile Bitcoin fiyatları arasında gerçekleştirilen korelasyon analizi sonucunda, 0.681 korelasyon katsayısı değeri elde edilmiş ve iki değişken arasında pozitif, aynı yönlü, iyi seviyede doğrusal bir ilişki olduğu ortaya konulmuştur. 
Diğer yandan, Tekbulut ve diğerleri (2020) özellikle toplantı yönetiminde duygu analizini ortaya koymak amacıyla doğal dil işleme yöntemlerini kullanmıştır. Duygu analizi için toplantı dokümanlarından yararlanılmıştır. Diğer bir deyişle, ekiplerin duygu analizi, retrospektif (geçmişe bakış) toplantılarında takım üyeleri tarafından yazılan metinsel veriler kullanılarak gerçekleştirilmiştir. Bu çalışmada amaç, toplantılar sonucundaki geri bildirimlerden ve yorumlardan yola çıkılarak takım üyelerinin duygularını analiz etmek ve negatif düşüncelerin izlenen ölçüm sonuçlarına etkisini izleyerek, negatif duyguya yol açan durumların olumlu düşüncelere yol açmasına katkı sağlamak olarak göze çarpmaktadır. Çalışmadan elde edilen sonuçlara göre, çalışmanın sürece en büyük katkısı sürecin gelişme aşamalarını daha şeffaf bir şekilde göstermektir.

Cusick ve diğerleri (2021) elektronik sağlık kaydı sistemlerindeki yapılandırılmamış klinik notlardan "mevcut" intihar düşüncesini tespit etmek için makine öğrenmesi yöntemlerini uygulamıştır. Bunun için; intihar düşüncesi riski taşıyan 600 hastadan oluşan bir kohort belirledikten sonra, 17.978 adet notu, eğitim ve doğrulama olarak ayırıp, etiketlemek için kurala dayalı bir doğal dil işleme yaklaşımı kullanmışlardır. Bu büyük klinik not külliyatını kullanarak, değerlendirilmek üzere çeşitli istatistiksel makine öğrenmesi modelleri- lojistik regresyon, destek vektör makineleri (Support Vector Machine), Naive Bayes sinıflandırıcı ve metin sınıflandırması için evrişimsel sinir ağı (Convolutional Neural Network) eğitmişlerdir. Manuel olarak incelenen bir test setinde $(n=837) \mathrm{CNN}$ modeli, "mevcut" intihar düşüncesi olan dokümanlarda \%94'lük bir doğruluk ve 0.82'lik bir F1 skoru elde ederek diğer tüm yöntemlerden daha iyi performans göstermiştir.

Literatürden de anlaşıldığı gibi doğal dil işleme yöntemlerinin en yaygın kullanım alanı fikir madenciliği ve duygu analizi uygulamaları olmaktadır. Bu bağlamda fikir madenciliği ve duygu analizi kavramlarına daha detaylı bakmak çalışma açısından çok kritiktir. Böylelikle fikir madenciliği ve duygu analizi çalışmalarının farklı sektörlerdeki farklı uygulamaları da daha geniş bir çerçevede ele alınabilecektir.

\section{Fikir Madenciliği ve Duygu Analizi Kavramları}

Fikir madenciliği (opinion mining) ve duygu analizi (sentiment analysis), kişilerin ürünler, hizmetler, kurumlar, olgular ve durumlar gibi farklı konular hakkındaki duygu, düşünce ve görüşlerinin çıarımına dayanan çalışmalar olarak ifade edilebilir. Duygu analizi çalışmalarında, kişilerin görüşlerini bildirdikleri tüm konular varlıklar olarak adlandırılmaktadır. Duygu analizindeki ana amaç, duygu ifadelerini oluşturan dört önemli bileşen olan varlık, özellik, duygu ve öznenin bir kısmının veya tamamının metin içerisinden farklı yöntemler kullanılarak çıkarımıdır (Özyurt \& Akcayol, 2018, s.670).

Kişilerin ürün, hizmet, kişiler, organizasyonlar vb. üzerindeki duygu, düşünce, yorum ve aksiyonlarını analiz eden (Liu, 2012, p.7) fikir madenciliği, yapılandırılmamış belgelerin içerdiği verilerden farklı istatistiksel modeller kullanarak, bilgi olarak da fikirlerin elde edilmesini sağlamayı amaçlamaktadır (Atalay \& Çelik, 2017, s.168).

Özellikle sosyal medyada verinin üstel olarak artması ve veri işlemenin maliyetinin azalması ile duygu analizi ve fikir madenciliği yeni bir araştırma konusu olarak ortaya çıkmaktadır. Örneğin bir ürün hakkında kullanıcı görüşlerinin farklı yöntemlerle pozitif, negatif veya nötr şeklinde analiz edilip işletmenin müşterilerine buna dayalı ürün önermesi veya kişiselleştirilmiş ürün deneyimi sunması fikir madenciliği ve duygu analizi sürecinin sonunda elde edilen bilgi çıkarımı sayesinde mümkün olabilmektedir. 
Fikir madenciliği aynı zamanda, araştırmanın teması olan konu hakkında ortaya atılan "karşılaştırmalı cümle" görevini ortaya koymayı amaçlamaktadır. Buna örnek olarak, iki ürün veya hizmetin karşılaştırılmasına dayalı otomatik bilgi çıkarımı verilebilir. Böylece markaların birbirlerine üstünlüğü ortaya konulabilmektedir (Aytekin \& Mayda, 2013, s.416). Bu da işletmelere rekabet analizi ve avantajı konusunda kritik katkılar sağlamaktadır.

Duygu analizi, fikir madenciliği ve öznellik analizi (Subjectivity Analysis), doğal dil işleme (Natural Language Processing), bilgi çıkarımı (Information Retrieval) ve veri madenciliğini (Data Mining) harmanlamakta ve bunlara dayalı çeşitli teknikleri birbirleriyle ilişkili olarak kullanmaktadır (Bakshi vd., 2016, p.15). Çeşitli veri kaynaklarından elde edilen veri setleri ve amaca yönelik olarak farklı yöntemlerin kullanılmasıyla duygular farklı düzeylerde analiz edilebilmektedir. Bir sonraki bölümde duygu analiz düzeyleri açıklanmaktadır.

\section{Duygu Analizi Düzeyleri}

Duygu analizi ve fikir madenciliği ile ilgili araştırmalar, çalışmanın kapsamına ve elde edilmiş olan veri setlerine göre farklı düzeylerde incelenebilmektedir. Bunlar; doküman düzeyinde duygu analizi (document level sentiment analysis), cümle düzeyinde duygu analizi (sentence level sentiment analysis), özellik düzeyinde/özellik(bakış) tabanlı duygu analizi (aspect level sentiment analysis) olarak üç farklı düzeyde incelenmektedir.

\section{Doküman Düzeyinde Duygu Analizi}

Doküman düzeyinde duygu analizi, doğası gereği çok cümleli metinleri içermektedir (Bhatia vd., 2015, p.2212). Bunun yanında, doküman düzeyinde duygu analizi, belli bir konuda ortaya konulan metinsel bir incelemeyi, olumlu veya olumsuz bir duyguyu ifade edecek şekilde, otomatik olarak sınıflandırmayı amaçlamaktadır (Moraes vd., 2013, p.621).

Doküman düzeyinde duygu analizi kapsamında, metinler bir bütün olarak cümle veya kelime detaylarına inilmeden incelenmektedir. Bir diğer ifadeyle, metinler bütün olarak ele alınmakta, derinlemesine bir ayrıma gidilmemektedir.

Doküman düzeyinde duygu analizinde, dokümanının tümünün duygu polaritesinin ortaya konulması hedeflenmektedir. Bu düzeyde, metin içerisindeki tek bir varlık hakkında görüş bildirildiğinden; birden fazla varlık hakkındaki görüş analiz edilememektedir. Bu durum, doküman düzeyinde duygu analizinin bazı avantaj ve dezavantajlarını da beraberinde getirmektedir. Avantaj olarak, belirli bir varlık için duygu polaritesinin tek bir metinden elde edilmesi düşünülebilir; fakat bunun yanında farklı varlıklar hakkındaki fikirlerin veya görüşlerin analiz edilememesi dezavantaj olarak değerlendirilmektedir (Shirsat vd., 2017, p.2).

\section{Cümle Düzeyinde Duygu Analizi}

Doküman düzeyinde duygu analizi, bir metnin tümünden ifade edilen genel bir görüşü belirtmeyi amaçlarken, cümle düzeyinde duygu analizi; tek bir cümlenin duygu polaritesinin (pozitif, negatif veya nötr) belirlenme sürecini gerçekleştirmeye çalışmaktadır (Basiri \& Kabiri, 2017, p.84).

Cümle düzeyinde duygu analizi her cümleyi ayrı bir girdi olarak almaktadır. Bu durumda temel varsayım ise, her cümlenin yalnızca bir görüş içermesi gerekliliği etrafında şekillenmektedir. Cümle düzeyinde duygu analizinin en temel iki görevi, öznellik sınıflandırması (cümlenin duygu içerip içermediğinin belirlenmesi) ve duygu sınıflandırması (sentiment classification) olarak ele alınabilmektedir. 
Cümle düzeyinde duygu analizinde, metnin içindeki her cümlenin duygu ifade edip etmediği belirlendikten sonra, duygu sınıflandırması yapılmaktadır. Özellikle Web 2.0 sistemlerinde kullanıcı yaratımlı olarak oluşturulan sosyal ağ içerik verilerindeki fikirlerin analiz edilmesi noktasında, bu düzey yaygın olarak kullanılmaktadır. Örneğin, bir e-ticaret firması için müşterilerinin Twitter üzerinden paylaştıkları görüşler, bu kapsamda değerlendirilebilmektedir. Bu süreçte yapay zekânın alt dallarından biri olan makine öğrenmesi yöntemleri sıklıkla kullanılmaktadır. (Jagtap \& Pawar, 2013, p.164).

\section{Özellik Düzeyinde / Özellik Tabanlı Duygu Analizi}

Özellik tabanlı duygu analizi, varlığın hangi özelliği için pozitif, hangi özelliği için negatif görüş bildirildiğinin belirlenmesini sağlamaktadır. Bir diğer ifadeyle, belirli bir varlığın yönü olan bir hedefe yönelik cümlenin duygu polaritesini çıarmayı amaçlamaktadır (Yang vd., 2019, p.464). Bu düzey aynı zamanda hedef tabanlı veya bakış tabanlı duygu analizi olarak da literatürde incelenmektedir.

Özellik tabanlı duygu analizinin en önemli fonksiyonları Özellik Çıkarımı (Aspect Extraction) ve Duygu Sınıflandırması (Aspect Sentiment Classification) olarak iki grupta ele alınmaktadır. Örnekle açıklanacak olursa, özellik çıkarımında amaç; bazı duyguların ifade edildiği konunun belli bir yönünü ortaya çıkarmaktır. Duygu sınıflandırılmasında ise, amaç; tüketici tarafından yapılan bir incelemede ifade edilen duyguyu çıkarmaktır (Karimi vd., 2020, p.2).

Özellik tabanlı duygu analizi hem kullanıcı hem de kurumsal bakış açısından büyük önem arz etmektedir. Kullanıcılar bir ürünü satın almadan, bir otel rezervasyonu yapmadan veya bir hizmeti kullanmadan önce farklı konularda bilgiye ihtiyaç duymaktadır. Bu nitelikte konuların analizi, organizasyonlar için de ürünlerini iyileştirme ve kullanıcı memnuniyetini ölçme bağlamında yardımcı olmaktadır (Amarouche vd., 2015, p.368).

Özellik tabanlı duygu analiz düzeyindeki en kritik nokta karşılaştırılmalı fikirlerin de sisteme katılmasıdır. Örneğin bir ürün için yapılan yorumun, aynı ürünün bir önceki yıl çıkarılmış olan versiyonuna göre veya işletmenin rakiplerinin çıardığı ürüne göre, hangi yönlerden olumlu, hangi yönlerden olumsuz olduğu incelenebilmektedir (Şeker, 2016, s.23). Bu durum da işletmelere rekabet avantajı kazandırmaktadır. Böylelikle duygunun ürünler bazında veya aynı ürünün farklı boyutları (zaman vb.) vurgulanarak analiz edilebilmesi, işletme açısından farklı seviyelerde farklı kararlar alınmasına olanak tanıyacaktır.

\section{Duygu Analizinde Kullanılan Yöntemler}

Duygu analizi amaçlı kullanılan yöntemleri temel olarak üç ana sınıfa ayırmak mümkündür. En genel anlamda duygu analiz yöntemleri; sözlük tabanlı yöntemler, makine öğrenmesi tabanlı yöntemler ve karma yöntemler olarak üç gruba ayrılmaktadır.

\section{Sözlük Tabanlı Yöntemler}

Sözlük tabanlı yöntemlerde veya sözlüğe dayalı yaklaşımda (lexicon-based approach), farklı dillerde bir veri sözlüğü kullanılarak burada geçen kelimeler üzerinden duygu polaritesi hesaplanmaktadır. Bu yaklaşımda, başlangıç aşaması olarak tohum (seed) veri seti ile başlanmaktadır; daha sonra sözlük farklı kelimeler eklenerek genişletilmektedir (Can \& Alatas; 2017, s.85). Kelime eşleştirme (word matching) sözlük tabanlı duygu sınıflandırması için geleneksel bir yöntem olarak vurgulanmaktadır. Bu yöntemde, veri sözlüğündeki her 
kelimenin olumlu ya da olumsuz duyguları kategorize etmek için kullanılabilecek duygu polaritesi bulunmaktadır (Park \& Kim, 2016, p.85).

Sözlük tabanlı yöntemlerde veri sözlükleri manuel ya da otomatik olarak oluşturulabilmektedir. Sözlük tabanlı yaklaşımın çoğunda, sıfatlar anlamsal yönelim (semantic orientation) göstergesi olarak kullanılmaktadır. Bu değerler tüm sözlükte derlenmektedir. Daha sonra tüm sıfatlar hedef metinden çıkarılmakta ve sözlük kullanılarak anlamsal yönelim değeri ile etiketlenmektedir (Kundi vd., 2014, p.239).

\section{Makine Öğrenmesi Tabanlı Yöntemler}

Makine öğrenmesi tabanlı yöntemlerde, özellikle denetimli öğrenme teknikleri sıklıkla kullanılmaktadır. Burada denetimli makine öğrenmesinin sık kullanılmasının temel nedeni, ilk aşamada hangi duygu içerdiği belli olan metinlerin yansıttıkları duyguya göre, pozitif, negatif, nötr gibi daha yüzeysel veya sinirli, eğlenceli, karamsar gibi daha detaylı etiketler kullanılarak uzman veya uzmanlar tarafından etiketlenmiş olmasıdır. Bir diğer ifadeyle, metin verisindeki duygu önceden belirlidir. Sonraki süreçte ise etiketlenmiş metin verisinden elde edilen eğitim setiyle model eğitilerek, etiketlenmemiş metinlerin hangi duygu sınıfına gireceğ $i$ belirlenmektedir. Bu süreç makine öğrenmesi yardımıyla otomatik olarak gerçekleşmektedir. Bunun için öncelikle metinlerdeki örneklerin TFxIDF, Word2Vec, Doc2Vec gibi temsil yaklaşımlarıyla temsil edilmesi gerekmektedir. Duygu analizinde en çok kullanılan sınıflandırma algoritmaları, Naive Bayes, Destek Vektör Makineleri, Karar Ağaçları, Yapay Sinir Ağlarıdır (Kılınç \& Başeğmez; 2018, s.90).

Özellikle yapay sinir ağlarının son yıllarda duygu analizi amaçlı sıklıkla kullanıldığı görülmektedir. Burada yapay sinir ağlarının model değerlendirme aşamasında ortaya koyduğu performans çoğu zaman geleneksel makine öğrenmesi yöntemlerini geride bırakmaktadır. Bir Python yazılım dili kütüphanesi olan "Gensim" arka planda çalıştırdığ yapay sinir ağıyla duygu analizi işlemlerini yüksek başarımlarla gerçekleştirebilmektedir.

Literatürde İngilizce için duygu sınıflandırması amaçlı çeşitli veri setleri bulunmakla birlikte, Türkçe için bu çabalara daha çok ihtiyaç duyulmaktadır. Bu amaçla da son yıllarda farklı araştırmacılar Türkçe metinlerden duygu sınıflandırması için veri setleri üretmektedir. Bunlardan biri TTC-3600 Benchmark veri setidir. Bu veri setinde Türkçe haber ve makaleler kullanılması kolay ve iyi dokümante edilmiş şekilde yer almaktadır (Kılınç vd., 2017, s.180). Buna ek olarak, makine öğrenmesi algoritmalarının, mutluluk, korku, öfke, üzüntü, tiksinme, şaşırma gibi farklı duyguların sınıflandırılması amaçlı etkin kullanılması için ortaya konan Türkçe TREMO veri seti de bulunmaktadır (Toçoğlu vd., 2019, p.721).

\section{Karma (Hibrit) Yöntemler}

Karma yöntemler sözlük tabanlı yöntemler ve makine öğrenmesi yöntemlerinin bir arada kullanılmasıyla yapılan duygu analizi çalışmalarını işaret etmektedir. Karma yöntemlerde birkaç yöntem farklı amaçlarla kullanılarak duygu analizi süreci gerçekleştirilmektedir.

\section{Toplum Çevirmenliği Araştırmalarında Fikir Madenciliği}

Dijital verilerin hızla arttığı günümüzde, işletmeler özellikle internette mevcut olan büyük veri yığınlarından; gelişme ve büyüme noktasında yararlanmak zorunda kalmaktadır. Çok yakın zamana kadar, dijital alanda dolaşan tüm bu veriler büyük ölçüde kullanılamazdı. Sosyal ağların gelişmesiyle birlikte; bireyler, markalar ve kuruluşlar hakkındaki duygu ve düşüncelerini sosyal medya platformları üzerinden paylaşmaya başlamıştır. Tüm bu halka 
açık ve ücretsiz veriler; özellikle pazarlama alanında "fikir madenciliği" alanının gelişmesi için önemli bir çıkış noktası olmuştur. Fikir madenciliği, çoğunlukla pazarlama alanında; kişilerin ürünler hakkındaki görüşlerini farklı yöntemlerle ortaya çıkarmaktadır. Bunun için en yaygın veri kaynağı, çevrimiçi metinlerin bulunduğu sosyal medya olmakla birlikte; web sayfaları, forumlar, anket yanıtları ve röportajlar da fikir madenciliği için kullanılabilmektedir.

Kişilerin; satın aldıkları bir ürün veya konakladıkları yer hakkındaki duygu ve düşüncelerini doğru bir şekilde analiz etmek; fikir beyan etmeyenlerin algıları hakkında da genelleştirilmiş duyguları yansıtabilme potansiyelini taşımaktadır. Bu durum bir işletmenin pazarlama ekibi düşünülecek olursa; yalnızca genel görüsslerin algılanması noktasında değil aynı zamanda bu duyguların arkasındaki itici gücün ne olduğunun da analiz edilmesine olanak tanıyacaktır. Etkin ve etkili fikir madenciliği sürecinin inşa edilmesiyle; ürün ya da markadaki kritik zayıflıklar veya güçlü yönleri ortaya çıkaran önemli bilgiler keşfedilebilecek; aynı zamanda bunlarla ilgili bazı kararların alınması sağlanacaktır. Bu durum; işletmeler için kârlılık ve pazar payı noktasında stratejik değişiklikler yapması gerekliliğini de ortaya çıarmaktadır. Bu değişiklikleri yapmak için gerekli olan bilgilerin tümü de fikir madenciliği yöntemiyle toplanıp analiz edilebilmektedir.

Birçok alanda kullanılabilen bu yöntemi sözlü çeviri araştırmalarında, özellikle de duygusallığın yoğun olduğu toplum çevirmenliği araştırmalarında kullanmak mümkündür. Fikir madenciliği ile duygu analizi yönteminin en büyük katkılarından biri kullanıcıların, sözlü çeviri bağlamında ise çevirmenlerin, duygu polaritesini pozitif, negatif veya nötr olarak belirleyebilmesidir. Fikir madenciliği yöntemi yapay öğrenme alanında daha çok sosyal medyada kullanıcıların söylemleri üzerinden duygu analizi amacıyla kullanılmaktadır. Fakat bu yöntemin sözlü çeviri araştırmalarına da entegre edilmesi mümkündür. Çevirmenlerin özellikle çalıştığı ortam ve çeviri kitleleri vb. konularla ilgili duygularını yansıtan görüşleri röportaj aracılığıyla elde edilebilmektedir. Ancak röportaj ile elde edilen veriler sezgisel olarak çıkarım yapılarak yorumlanabilirken, fikir madenciliği ile duygu analizinin en önemli katkılarından biri, verilerin makine öğrenmesi yöntemleriyle istatistiksel olarak daha somut bir şekilde ortaya konulmasıdır. Diğer bir deyişle, hâlihazırda röportajla elde edilen veriler bu yöntem sayesinde istatistiksel açıdan desteklenip doğrulanmış olmaktadır. Fikir madenciliği yöntemini diğer nitel ve nicel yöntemlerden ayıran en büyük özelliği ise verilerden kelime bulutu oluşturarak kullanıcılar tarafından en sık tekrarlanan kelimeleri öne çıkarmasıdır. Böylelikle kullanıcıların aslında neye vurgu yaptığı daha kolay bir şekilde anlaşılmaktadır. Röportaj sırasında çevirmenler de bazı düşüncelerini açıkça ifade edemeyebilmektedir. Fakat bu yöntem sayesinde çevirmenlerin röportaj sırasında sıklıkla tekrarladığı kelimeleri ortaya çıkararak aslında bilinçaltında yatan düşünceler hakkında yorum yapabilmek mümkündür. Nitekim literatürde sağlık alanında uygulanan bu yöntem sayesinde hastaların intihara meyilli olduğunu tespit eden çalışmaya da rastlanmaktadır. Benzer sonuçları veya daha farklı sorunları çevirmenler açısından da elde etmek mümkündür. Bu yöntemin amacı, var olan negatif düşünceleri saptaması ve bu negatif düşünceleri olumluya döndürme konusunda olanak sunmasıdır. Örneğin, bir çevirmenin hastane çevirmenliği alanıyla ilgili yorum yaparken en çok "psikoloji" kelimesini kullandığ tespit edilmişse, özellikle psikoloji hakkında bir eksiklik veya sıkıntı olduğu yargısına varılabilir. Nihayetinde ise çevirmenlere psikolojik destek/ eğitim sağlanarak olumsuz olan bu durumun iyileştirilmesi sağlanabilmektedir. Araştırmadan çıkabilecek herhangi bir olumsuz durum, çeviri kalitesini de etkileyeceğinden işvereni de olumsuz yönde etkileyebilmektedir. Bu sebeple fikir madenciliği yöntemi duygudurumun ortaya çıkarılmasını sağlayan etkili bir yöntemdir. 
Diğer yandan, bu çalışma istatistiksel verilere odaklandığ1 için makine öğrenmesi tabanlı yöntemler kategorisinde incelenebilmektedir. Bunun için, çevirmenlerle yapılan röportajların transkriptleri çıkartılarak bütün bir doküman şeklinde sisteme yüklenmesi ve genel olarak bir duygudurum çıarımı elde edilebilmesi mümkündür. Çevirmenlerin verdiği cevapları bir bütün olarak göz önünde bulundurup genel bir sonuç sunacağ iç̧in bu çalışma doküman düzeyinde duygu analizi kapsamına girmektedir. Fakat, bir bütün olarak değil, çevirmenlerin sadece çalıştığı ortamla ilgili duygudurumunu ortaya çıkarabilecek spesifik sorulara verdiğ cevaplara odaklanılarak cümle düzeyinde duygu analizi de mümkündür. Hangi yöntemlerle ve hangi düzeyde duygu analizi yapılırsa yapılsın, fikir madenciliği yöntemi çevirmenlerin çalıştığı ortam ve kitleyle ilgili pozitif, negatif veya nötr olarak sahip oldukları duyguları ortaya çıarmaktadır. Negatif duygular ise kaynağına inilerek bu konuda iyileştirme yapılması ve gerekirse negatif duygulara yol açan sebepler üzerinde çevirmenlere eğitim verilerek çeviri performansının ve çeviri kalitesinin artırılması sağlanabilmektedir. Bu amaç doğrultusunda en somut ve güvenilir veriyi ise sağlık, turizm, politika gibi birçok alanda uygulanan fikir madenciliği yöntemi ile elde etmek mümkündür.

\section{Sonuç ve Öneriler}

Teknolojinin hayatımıza etkileri her geçen gün artmaktadır. Sözlü çeviri sektöründe de teknoloji kullanımının birçok yenilik ve kolaylık sağladığı aşikârdır. Teknolojinin sağladığı faydalar hem bilim insanlarının hem de sektör çalışanlarının ilgisini çekmektedir. Bu çalışma da veri biliminde birçok sektörden kullanıcıların duygu ve düşüncelerini istatistiksel olarak ölçmek için kullanılan "fikir madenciliği" yönteminin sözlü çeviri araştırmalarına da entegre edilebileceğini ileri sürmektedir. Özellikle toplum çevirmenliği ortamlarında çeviri yapan çevirmenlerin üzerindeki duygusal baskı diğer sözlü çeviri ortamlarında çalışan çevirmenlere göre daha fazladır ve bu duygusal baskı, çevirmenin çeviri kalitesini de olumsuz yönde etkileyebilmektedir. Bu sebeple, özellikle toplum çevirmenlerinin çalıştıkları ortam ve çeviri yaptıkları kitle ile ilgili duygudurumlarının ortaya konulması ve varsa negatif düşüncelere yol açan sebeplere odaklanılarak bu negatif durumlara çözümler üretilmesi çevirmenin çeviri performansını olumlu yönde etkileyerek çeviri kalitesinin artırılmasına yardımcı olabilecektir. $\mathrm{Bu}$ amaçla, bu çalışmada sözlü çeviri araştırmalarında teknolojinin önemi ve toplum çevirmenliği alanında duygu faktörünün çeviriye olası etkilerinden bahsedildikten sonra yapay zekânın alt dallarından biri olan doğal dil işleme betimleyici bir yaklaşımla ayrıntılı olarak aktarılmış ve özellikle "çevirmen" grubuna odaklanılarak toplum çevirmenliğinde fikir madenciliği ile duygu analizi yönteminin ne yönden katkı sağlayacağ 1 üzerinde durulmuştur. $\mathrm{Bu}$ çalışmada özellikle çevirmenler üzerinden bir öneri sunulmuş olmasına rağmen, fikir madenciliği yönteminin çeviri kullanıcılarına da çeviri algısı ile ilgili olarak uygulanması mümkündür ve bu çalışma; ileriki çalışmalar için ışık tutarak sözlü çeviride yeni bir uygulama alanı sunmayı hedeflemektedir. 


\section{Kaynakça}

Adalı, E. (2012). Doğal Dil İşleme. Türkiye Bilişim Vakfı Bilgisayar Bilimleri ve Mühendisliği Dergisi, 5(2).

Amarouche, K., Benbrahim, H., \& Kassou, I. (2015). Product Opinion Mining for Competitive Intelligence. Procedia Computer Science, 73, 358-365.

Arzık-Erzurumlu, Ö. (2020). Employing Podcasts as a Learning Tool in Interpreter Training: A Case Study. Maria Dolores Rodriguez Melchor, İldiko Horvath ve Kate Ferguson (Eds). The Role of Technology in Conference Interpreter Training içinde. (pp. 179- 202). Peter Lang.

Atalay, M., \& Çelik, E. (2017). Büyük Veri Analizinde Yapay Zekâ ve Makine Öğrenmesi Uygulamaları. Mehmet Akif Ersoy Üniversitesi Sosyal Bilimler Enstitüsü Dergisi, 9(22), 155-172.

Bakshi, R. K., Kaur, N., Kaur, R., \& Kaur, G. (2016). Opinion mining and sentiment analysis. 2016 3rd International Conference on Computing for Sustainable Global Development (INDIACom), 452-455.

Balkul, İ. \& Akıncı, Ş. (2019). Sözlü C,eviride Kullanılan Teknolojik Araçların Sınıflandırılması." Rumelide Dil ve Edebiyat Araștırmaları Dergisi. 2019.15 (Haziran), 391- 406.

Basiri, M. E., \& Kabiri, A. (2017). Sentence-Level Sentiment Analysis in Persian. 2017 3rd International Conference on Pattern Recognition and Image Analysis (IPRIA), 84-89. https://doi.org/10.1109/PRIA.2017.7983023

Bhatia, P., Ji, Y., \& Eisenstein, J. (2015). Better Document-level Sentiment Analysis from RST Discourse Parsing. arXiv:1509.01599 [cs]. http://arxiv.org/abs/1509.01599

Blair, D. T \& Ramones, V. A. (1996). Understanding Vicarious Traumatization. Journal of Psychosocial Nursing and Mental Health, Vol 34(11), 24-30.

Braun, S. (2019). Technology and Interpreting M. O'Hagan (Ed.), Routledge Handbook of Translation and Technology içinde New York: Routledge

Canım Alkan, S. (2013). Lisans düzeyinde çeviri eğ̈timiminde teknoloji eğ̈timinin yeri. $\dot{I} . \ddot{U}$ C,eviribilim Dergisi. ss. 127-147.

Canım Alkan, S. (2017). Bulut tabanlı bir çeviri yönetim sisteminin çevirmenler açsından avantaj ve dezavantajları üzerine bir degerlendirme. Electronic Turkish Studies. 12(23), 69-88

Corsellis, A. (2008). Public Service Interpreting: The First Steps. London: Palgrave Macmillan.

Cusick, M., Adekkanattu, P., Campion Jr, T. R., Sholle, E. T., Myers, A., Banerjee, S., ... \& Pathak, J. (2021). Using Weak Supervision and Deep Learning to Classify Clinical Notes for Identification of Current Suicidal Ideation. Journal of Psychiatric Research.136. 95-102.

Çalış, K., Gazdağı, O., \& Yıldız, O. (2013). Reklam İçerikli Epostaların Metin Madenciliği Yöntemleri ile Otomatik Tespiti. Bilişim Teknolojileri Dergisi, 6(1), 1-7.

Çılgın C., Ünal, C., Alıcı, S., Akkol, E., \& Gökşen, Y. (2020). Metin Sınıflandırmada Yapay Sinir Ağları ile Bitcoin Fiyatları ve Sosyal Medyadaki Beklentilerin Analizi. Mehmet Akif Ersoy Üniversitesi Uygulamalı Bilimler Dergisi, 4(1), 106-126. 
Deng, L., \& Liu, Y. (2018). A Joint Introduction to Natural Language Processing and to Deep Learning. Deng, L., \& Liu, Y. (Ed.), Deep Learning in Natural Language Processing içinde (pp. 1-22). Springer.

Diriker, E. (2010). Simultaneous Conference Interpreting and Technology. Yves Gambier ve Luc Van Loorsdaer (Eds.), Handbook of Translation Studies içinde (pp. 329- 332). John Benjamins Publishing Company: Amsterdam/ Philadelphia

Donovan C. (2006) “Trends - Where is Interpreting heading and how can training courses keep up?". Contribution at the EMCI conference: The Future of Conference Interpreting: Training, Technology and Research, 30 June - 1 July 2006, http://www.emcinterpreting.org/ repository/pdf/UoW_conf_06_C.Donovan.pdf

Duman, N. (2019). Duygudurum Düzenlemenin Çevirideki Önemi. Fadime Çoban ve Mehmet Cem Odacıoğlu (Eds.) Çevirmen Psikolojisi içinde (ss. 175- 184): Gece Akademi.

Fantinuoli, C. (2018). Interpreting and Technology: The Upcoming Technological Turn in Interpreting and Technology, Claudio Fantinuoli (Ed.). (pp. 1-12). Berlin: Language Science Press

Goldberg, Y. (2017). Neural Network Methods for Natural Language Processing. Synthesis Lectures on Human Language Technologies, 10(1), 1-309.

Jagtap, V. S., \& Pawar, K. (2013). Analysis of Different Approaches to Sentence-level Sentiment Classification. International Journal of Scientific Engineering and Technology, 2(3), 164- 170.

Kahraman, R. (2010). Göç ve Çeviri: İltica Başvurularında Sözlü Çeviri Uygulamaları ve Toplum Çevirmeninin Rolü (Yayımlanmamış Doktora Tezi). İstanbul Üniversitesi: İstanbul

Karimi, A., Rossi, L., \& Prati, A. (2020). Improving BERT Performance for Aspect-Based Sentiment Analysis. arXiv preprint arXiv:2010.11731.

Kay, M. (2004). Computational Linguistics. Mitkov, R., (Ed.). The Oxford Handbook of Computational Linguistics içinde (ss. 25-31). Oxford University Press.

Kılınç, D. \& Başeğmez, N. (2018). Uygulamalarla Veri Bilimi. İstanbul: Abaküs Yayınevi.

Kılınç, D., Özçift, A., Bozyiğit, F., Yıldırım, P., Yücalar, F., \& Borandağ, E. (2017). TTC-3600: A New Benchmark Dataset For Turkish Text Categorization. Journal of Information Science, 43(2), 174-185.

Kundi, F. M., Khan, A., Ahmad, S., \& Asghar, M. Z. (2014). Lexicon-Based Sentiment Analysis in The Social Web. Journal of Basic and Applied Scientific Research, 4(6), 238-248.

Kuşçu, E. (2015). Çeviride Yapay Zekâ Uygulamaları. Atatürk Üniversitesi Kazım Karabekir Eğitim Fakültesi Dergisi, (30), 45-58.

Liu, B. (2012). Sentiment Analysis and Opinion Mining. Williston: Morgan \& Claypool Publishers.

Liu, H. (2018). Help or Hinder? The Impact of Technology on the Role of Interpreters. FITISPos International Journal. 5(1), 13- 32.

Mayda, İ., \& Aytekin, Ç. (2013). Sosyal Medyada Rekabet Analizi İçin Karşılaştırma Görevine Yönelik Fikir Madenciliği Modeli. JAMMO ISSN 2146-3328, 7(27), 414-425. 
Moraes, R., Valiati, J. F., \& Neto, W. P. G. (2013). Document-level Sentiment Classification: An Empirical Comparison between SVM and ANN. Expert Systems with Applications, 40(2), 621633.

Mouzourakis, P. (2000). Interpretation Booths for the Third Millennium. Communicate! March-April 2000, http://www.aiic.net/View Page.cfm/page131.htm.

Öztürk, E. (2017). The Medium Turn in Interpreting Studies. Trakya Üniversitesi Edebiyat Fakültesi Dergisi. 7(14), 108- 119.

Özyurt, B., \& Akcayol, M. A. (2018). Fikir Madenciliği ve Duygu Analizi, Yaklaşımlar, Yöntemler Üzerine Bir Araştırma. Selçuk Üniversitesi Mühendislik, Bilim ve Teknoloji Dergisi, 6(4), 668-693.

Park, S., \& Kim, Y. (2016). Building Thesaurus Lexicon Using Dictionary-Based Approach for Sentiment Classification. 2016 IEEE 14th International Conference on Software Engineering $\begin{array}{llll}\text { Research, } & \text { Management } & \text { 39-44. }\end{array}$ https://doi.org/10.1109/SERA.2016.7516126

Pınarbaşı, F., \& Canbolat, Z. N. (2018). Evaluation of Augmented Reality Mobile Applications in Turkey Market: A Data Mining Approach to Consumer Reviews. Kapucu, H., \& Akar, C. (Eds.) Changing Organizations: From the Psychological and Technological Perspectives içinde (pp. 187-197). IJOPEC Publication.

Poibeau T. (2017). The 1966 ALPAC report and its consequences. Machine Translation Poibeau T. (Ed). Cambridge: MIT Press. 75-89

Pöchhacker, F. (1999). 'Getting Organized': The Evolution of Community İnterpreting. Interpreting.4(1), 125- 140

Pöchhacker, F. (2004). Introducing Interpreting Studies. Londres. Routledge

Pöllabauer, S. (2002). Community Interpreting als Arbeitsfeld- Vom Missionarsgeist und von moralischen Dilemmata. Johanna Best ve Slyvia Kalina (Eds.), Übersetzen und Dolmetschen: Eine Orientierungshilfe içinde (pp. 286- 298). Tubingen ve Basel: Francke.

Sanlı, F. (2019). Belediye Çalışanlarında Özgünlük, Olumlu veya Olumsuz Duygu Durum ve Tükenmişlik Durumunun Değerlendirilmesi. (Yayınlanmamış Yüksek Lisans Tezi). Maltepe Üniversitesi, Sosyal Bilimler Enstitüsü, İstanbul

Shirsat, V. S., Jagdale, R. S., \& Deshmukh, S. N. (2017). Document Level Sentiment Analysis from News Articles. 2017 International Conference on Computing, Communication, Control and Automation (ICCUBEA), 1-4. https://doi.org/10.1109/ICCUBEA.2017.8463638.

Şahin, M. (2013). Technology in Translator Training Programs: The Case of Turkey. Journal of Faculty of Letters 30(2), 173-189.

Şahin, M. (2015). Çevirmen Adaylarının Gözünden İngilizce-Türkçe Bilgisayar Çevirisi ve Bilgisayar Destekli Çeviri: Google Deneyi (Machine Translation and Computer-Aided Translation for English-Turkish from the Viewpoint of Prospective Translators: The Google Experiment). Çeviribilim ve Uygulamaları Dergisi (Journal of Translation Studies): 21, 43-59.

Şahin, M. (2016) Translation Technologies: Promises and Challenges for a Less Commonly Translated Language. Translatologia1, pp.1-22. 
Şahin, M. \& Eraslan, Ş. (2017). Sözlü Cẹviri Egĭtiminde Yeni Yaklaşımlar: Sanal Dünyalar. Neslihan Kansu-Yetkiner\& Mehmet şahin (Eds.) Dilbilim Çeviribilim Yazıları içinde (ss. 193206): Anı Yayınları

Şan, F. \& Kahraman Duru, R. (2020). COVIDD-19 koşullarında sağlık çevirmenliği hizmetleri ve toplum çevirmenliğinde "Yeni Normal"'i düşünmek. RumeliDE Dil ve Edebiyat Araştırmaları Dergisi. 2020.20 (Eylül). 816- 843.

Şeker, Ş. E. (2016). Duygu Analizi (Sentimental Analysis). YBS Ansiklopedi, 3(3), 21-36.

Şener, O. (2017). Healthcare Interpreting in Turkey: Role and Ethics from a Sociological Perspective. (Yayımlanmamış Yüksek Lisans Tezi). Dokuz Eylül Üniversitesi, Sosyal Bilimler Enstitüsü, İzmir

Tekbulut, T., Canbaz, N., \& Kaya, T. Ö. (2020, Ekim). Machine Learning Application in LAPIS Agile Software Development Process. 2020 Turkish National Software Engineering Symposium (UYMS) (ss. 1-6). IEEE.

Toçoğlu, M., A., Çelikten, A., Aygün, İ., \& Alpkoçak, A. (2019). Türkçe Metinlerde Farkl1 Makine Öğrenmesi Yöntemlerinin Karşılaştırılması. Dokuz Eylül Üniversitesi Mühendislik Fakültesi Fen ve Mühendislik Dergisi, 21(63), ss.719-725.

Uçan, A. \& Akçapınar Sezer, E. (2020). Türkçe Bilgisayarlı Dil Bilimi Çalışmalarında His Analizi. Türk Dili Araştırmaları Yıllığı-BELLETEN, 70, ss.193-210.

Valero-Garcés, C. (2005). Emotional and Psychological Effects on Interpreters in Public Services: A Critical Factor to Bear in Mind. Translational Journal, 9(3), 1-14.

We are Social (2021). Digital 2021. https://wearesocial.com/digital-2021. Erişim Tarihi: 18.02.2021.

Yang, C., Zhang, H., Jiang, B., \& Li, K. (2019). Aspect-Based Sentiment Analysis with Alternating Coattention Networks. Information Processing $\mathcal{E}$ Management, 56(3), 463-478.

Young, T., Hazarika, D., Poria, S., \& Cambria, E. (2018). Recent Trends in Deep Learning Based Natural Language Processing. IEEE Computational intelligence Magazine, 13(3), 5

\section{Açıklamalar}

Sayfa 4'de yer alan Donovan (2006)'dan yapılan alıntı Olcay Şener Erkırtay tarafından İngilizceden Türkçeye çevrilmiştir. 